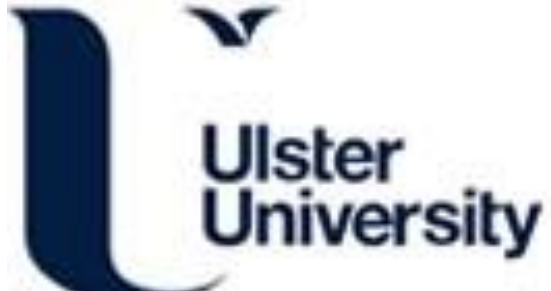

The Effect of Age on the Temporal Summation of Achromatic Perimetric Stimuli

Redmond, T., Garway-Heath, D., Zlatkova, M., Anderson, R., \& Mulholland, P. (2015). The Effect of Age on the Temporal Summation of Achromatic Perimetric Stimuli. Investigative Ophthalmology and Visual Science, 56, 6467-6472. https://doi.org/10.1167/iovs.15-16920

Link to publication record in Ulster University Research Portal

\section{Published in:}

Investigative Ophthalmology and Visual Science

Publication Status:

Published (in print/issue): 01/10/2015

DOI:

10.1167/iovs. $15-16920$

\section{Document Version}

Publisher's PDF, also known as Version of record

\section{General rights}

Copyright for the publications made accessible via Ulster University's Research Portal is retained by the author(s) and / or other copyright owners and it is a condition of accessing these publications that users recognise and abide by the legal requirements associated with these rights.

\section{Take down policy}

The Research Portal is Ulster University's institutional repository that provides access to Ulster's research outputs. Every effort has been made to ensure that content in the Research Portal does not infringe any person's rights, or applicable UK laws. If you discover content in the Research Portal that you believe breaches copyright or violates any law, please contact pure-support@ulster.ac.uk. 


\title{
The Effect of Age on the Temporal Summation of Achromatic Perimetric Stimuli
}

\author{
Pádraig J. Mulholland, ${ }^{1,2}$ Tony Redmond, ${ }^{3}$ David F. Garway-Heath, ${ }^{1}$ Margarita B. Zlatkova, ${ }^{2}$ \\ and Roger S. Anderson ${ }^{1,2}$
}

${ }^{1}$ National Institute for Health Research (NIHR) Biomedical Research Centre at Moorfields Eye Hospital NHS Foundation Trust and UCL Institute of Ophthalmology, London, United Kingdom

${ }^{2}$ Vision Science Research Group, School of Biomedical Sciences, University of Ulster, Coleraine, Northern Ireland, United Kingdom ${ }^{3}$ School of Optometry and Vision Sciences, Cardiff University, Cardiff, United Kingdom

Correspondence: Pádraig J. Mulholland, Moorfields Eye Hospital, 162 City Road, London EC1V 2PD, UK; padraig.mulholland@moorfields.nhs. uk.

Submitted: March 20, 2015

Accepted: August 10, 2015

Citation: Mulholland PJ, Redmond T, Garway-Heath DF, Zlatkova MB, Anderson RS. The effect of age on the temporal summation of achromatic perimetric stimuli. Invest Ophthalmol Vis Sci. 2015;56:6467-6472. DOI:10.1167/iovs.15-16920
Purpose. To examine the temporal summation of a Goldmann III-sized stimulus under the conditions of standard automated perimetry in healthy participants of varying age.

Methods. Twenty-seven healthy individuals of varying age (24-80 years) were tested. Achromatic contrast thresholds were measured for seven $0.48^{\circ}$ diameter (near Goldmann III) spot stimuli of varying presentation duration (1-24 frames, $1.8-191.9 \mathrm{~ms}$ ) at $8.8^{\circ}$ eccentricity in the visual field along the $45^{\circ}, 135^{\circ}, 225^{\circ}$, and $315^{\circ}$ meridians. All stimuli were displayed on a CRT display with a background set to $10 \mathrm{~cd} / \mathrm{m}^{2}$. Iterative two-phase regression analysis was used to estimate the critical duration from each localized temporal summation function.

REsults. A significant decrease in contrast sensitivity for all stimulus durations examined in this study was observed with increasing age in both the superior and inferior hemifield $(P<$ 0.001). Despite this, no significant change in the critical duration was observed as a function of age in either the superior $\left(r^{2}=9.1 \times 10^{-9}, P=0.99\right)$ or inferior hemifield $\left(r^{2}=2.4 \times\right.$ $10^{-5}, P=0.98$ ).

Concuusions. Age-related changes in the visual system, although leading to a reduction in contrast sensitivity, are not accompanied by a change in temporal summation for a detection task with an achromatic $0.48^{\circ}$ diameter spot stimulus. This is important to know when proceeding to examine temporal summation changes in diseases like glaucoma.

Keywords: temporal summation, perimetry, aging
$\mathrm{V}$ arious temporal and spatial aspects of visual processing are known to change with increasing age. ${ }^{1}$ Many of these changes can be attributed to optical or neural variations in the aging visual system. ${ }^{2-6}$ For example, retinal illuminance decreases with age secondary to pupil miosis ${ }^{7}$ and changes in the transmission spectra of the cornea and crystalline lens. ${ }^{8}$ Changes in photoreceptor structure and density have also been demonstrated whereby rods have been reported to undergo morphologic changes, resulting in the convolution ${ }^{9}$ and subsequent increase in the area of outer segments. ${ }^{10}$ In a similar manner, cone morphology ${ }^{11}$ and photopigment density ${ }^{12}$ alter as part of the aging process. Lower $\operatorname{rod}^{10}$ and cone density $^{13}$ has also been shown to be associated with age. Retinal ganglion cell (RGC) number is strongly correlated with age, as demonstrated in psychophysical, ${ }^{14}$ histologic, ${ }^{15}$ and imaging ${ }^{16}$ studies. A neural reorganization at the level of the retina has also been observed with increasing age in the absence of pathology. ${ }^{17,18}$ In addition, Devaney and Johnson ${ }^{19}$ reported approximately $50 \%$ of cortical neurons to be lost throughout life, with the "quality" of the remaining cells also being questioned.

Although temporal resolution is known to be influenced by age, as evidenced by a decrease in critical flicker fusion (CFF) frequency in older individuals, ${ }^{20}$ controversy surrounds the effect of age on the temporal summation of incremental aperiodic stimuli, such as those commonly used in clinical tests of the visual field. It is well known that, for a range of short duration stimuli, the product of stimulus luminance and duration is constant, with the result that energy remains constant at threshold. This relationship, described as complete temporal summation, is governed by Bloch's law. ${ }^{21}$ The point at which this reciprocal relationship breaks down is called the critical duration and may be influenced by a variety of factors including stimulus area, ${ }^{22,23}$ background luminance ${ }^{22}$ and psychophysical task. ${ }^{24}$ The physiological basis of temporal summation and the critical duration does, however, remain a matter of debate within the literature. It has been hypothesized that photoreceptors, ${ }^{25,26} \mathrm{RGCs},{ }^{27,28}$ and higher visual areas ${ }^{29,30}$ each play a role in the integrative process. Battersby and Schuckman $^{31}$ proposed that temporal summation is likely mediated by a synthesis of photochemical, neuroretinal and central processing, rather than reflecting function at a single locus in the visual pathway. As each of these anatomic loci has been shown to undergo age-related degradation in an otherwise healthy visual system, one may hypothesize that temporal summation, specifically the critical duration, might also be associated with age to maintain a constant signal-to-noise ratio.

A number of investigators have examined the effect of subject age on temporal summation, with vastly conflicting results. Fulton et al. ${ }^{32}$ reported the critical duration to be shorter in a group of dark-adapted 10-week-old infants compared with adult participants, when estimated using the 
amplitude of the $b$-wave component of ERG traces. This difference was attributed to an immaturity in the rod pathway in infants. Conversely, Eriksen et al. ${ }^{33}$ reported the critical duration for an orientation resolution task using a Landolt- $\mathrm{C}$ stimulus to be greater in participants aged 50 to 55 years compared with those aged 30 to 35 years. Using sinusoidal gratings of varying contrast and fixed spatial frequency (7.5 and $0.42 \mathrm{cyc} / \mathrm{deg}$ ), Sturr et al. ${ }^{34}$ reported no difference in the critical duration between young (mean: 25 years) and old (mean: 66 years) observers in a detection task. A later study by Dannheim and Drance, ${ }^{35}$ using achromatic perimetric stimuli of diameter $0.75^{\circ}$ and a background of $3.2 \mathrm{~cd} / \mathrm{m}^{2}$, also reported the shape of temporal summation functions to be independent of age at a variety of locations across the central visual field. However, no estimates of the critical duration were generated in the study.

Knowledge of the critical duration and how this varies with increasing age is of importance for the selection of an appropriate stimulus duration for use in standard automated perimetry (SAP). ${ }^{36}$ Currently, stimulus durations in the range 100 to $200 \mathrm{~ms}$ are used based upon assumptions about the course of temporal summation for perimetric stimuli and the minimum latency of voluntary saccadic eye movements. ${ }^{37}$ Specifically, it is suggested that the critical duration remains constant at 100 ms with no summation occurring after this point. ${ }^{38,39}$ Thus, contrast thresholds have traditionally been assumed to be independent of the effects of stimulus duration for stimuli $>100 \mathrm{~ms}$ duration. It has also been assumed that observers cannot initiate a saccade to view a stimulus presentation foveally when stimulus presentation duration is $\leq 200 \mathrm{~ms}$. Recent work of ours ${ }^{40}$ has, however, demonstrated that the critical duration for a $0.48^{\circ}$ diameter near-Goldmann III (GIII) stimulus under the conditions of SAP is probably significantly shorter than $100 \mathrm{~ms}$, with partial summation being measureable for stimuli of duration 100 to $200 \mathrm{~ms}$ at $8.8^{\circ}$ eccentricity in the visual field. No previous work has yet examined the effect of age on the temporal summation of SAP stimuli.

The aim of this study was to investigate the temporal summation of GIII stimuli in subjects of varying age, under the conditions of SAP. Knowledge of how temporal summation might change in healthy participants with increasing age is important for the appropriate selection of stimulus duration in SAP. It will also facilitate a comparison with any changes that may occur secondary to disease such as glaucoma (see accompanying paper $^{41}$ ).

\section{METHODS}

\section{Participants}

Twenty-seven volunteers ranging in age from 24 to 80 years (mean: 55 years, SD: 10 years) were recruited for this study. Twenty-four of these participants were recruited and tested at Moorfields Eye Hospital (MEH), London, with the remaining three participants being recruited and tested at the University of Ulster, Coleraine (UUC). All had intraocular pressures within normal limits ( $\geq 11 \mathrm{~mm} \mathrm{Hg}$ and $\leq 21 \mathrm{~mm} \mathrm{Hg}$ ) and no detectable ocular disease. Peripapillary retinal nerve fiber layer thickness was within normal limits in both eyes (Spectralis optical coherence tomographer; Heidelberg Engineering $\mathrm{GmbH}$, Heidelberg, Germany). Spherical refractive error was within \pm 6.00 diopters (D) in any meridian with astigmatism $\leq 2.0$ diopters cylinder. Corrected visual acuity was 20/20 (6/6) or better in the test eye for all participants. The data for a selection of subjects $(n=15)$ recruited and tested in this study were also used as control data in the accompanying paper examining temporal summation in glaucoma. ${ }^{41}$

Ethical approval for this study was gained from the London Central NRES Committee and the University of Ulster Biomedical Sciences Research Ethics Committee. Informed consent was obtained from each participant prior to data collection and the study conformed to the tenets of the Declaration of Helsinki.

\section{Apparatus and Stimuli}

Stimuli were generated on a $\gamma$-corrected 21" achromatic CRT monitor (Phillips FIMI MGD-403, pixel resolution $976 \times 1028$; frame rate $121 \mathrm{~Hz}, \mathrm{MEH}$ site; Ampronix, Irvine, CA, USA) or a $\gamma$ corrected 21" CRT monitor (Sony GDM F500-PST, pixel resolution $700 \times 800$; frame rate $120 \mathrm{~Hz}$, UUC site; Sony Corp., Tokyo, Japan;) with a stimulus generator (ViSaGe MKII; Cambridge Research Systems, Rochester, UK) and the CRS toolbox (version 1.27) for MATLAB (version R2011a, MathWorks, Inc., Natick, MA, USA). The background luminance of each monitor was $10 \mathrm{~cd} / \mathrm{m}^{2}$, with the maximum luminance of stimuli being 366 and $90 \mathrm{~cd} / \mathrm{m}^{2}$ for the Phillips and Sony monitors, respectively. The chromaticity coordinates of both the background and stimulus were $x=0.258$ and $y=0.257$, as measured with a spectrophotometer (ColorCal-II; Cambridge Research Systems, Rochester, UK). Refractive error was determined foveally for the viewing distance using retinoscopy, followed by subjective refinement by an experienced optometrist after pupil dilation $(\geq 7 \mathrm{~mm})$ in the test eye using tropicamide hydrochloride $1 \%$. Full-aperture trial lenses were used where refractive correction was required. During each test, participants placed their chin in a rest and forehead against a bar to view the CRT display at a distance of $60 \mathrm{~cm}$ in an otherwise darkened room. Responses were collected with a response pad (Cedrus RB-530; Cedrus Corp., San Pedro, CA, USA).

Temporal summation functions were generated for a stimulus close in size to a GIII stimulus (diameter $0.48^{\circ}$ ). To achieve this, contrast thresholds were measured for seven stimuli of different duration (1-24 frames, Bridgeman ${ }^{42}$ duration: $1.8-191.9 \mathrm{~ms}$ ), at $8.8^{\circ}$ visual field eccentricity along the $45^{\circ}, 135^{\circ}, 225^{\circ}$, and $315^{\circ}$ meridians.

\section{Psychophysical Procedure}

For each participant, all data were collected within a single 2.5-hour session, which included regular rest periods. To ensure each participant was familiar with the experimental apparatus and task required, a practice session was provided before commencing the psychophysical tests. Contrast thresholds were measured for each stimulus duration in separate, randomly ordered runs. In each run, thresholds were measured at each location with a randomly interleaved 1/1 staircase and a "Yes/No" procedure. Participants were asked to press a response button if a stimulus was detected. If a response was not collected within a specified window of $1.2 \mathrm{~s}$ following stimulus offset, it was assumed that the stimulus was unseen. After a "seen" response, stimulus contrast was decreased by $0.05 \mathrm{log}$ units and after an "unseen" response, it was increased by $0.05 \mathrm{log}$ units. Each staircase terminated after six reversals, with threshold taken as a mean of the final four reversal values. Threshold values corresponded to the $50 \%$ seen point on a psychometric function. ${ }^{43}$ False positive catch-trials ( $0 \%$ contrast stimuli) were also presented during each test. A false positive rate exceeding $20 \%$ resulted in the data being discarded, the subject readvised, and that run repeated. 

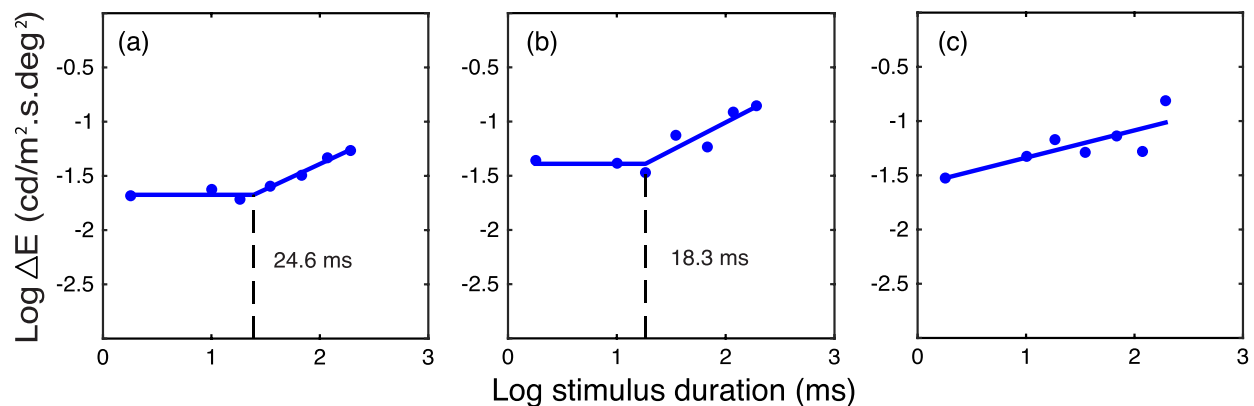

Figure 1. Example temporal summation functions for individual test locations in this study including: (a) an excellent example, (b) an average example, and (c) an example of a summation function that was excluded from further analysis. The estimated critical duration value is also included for reference.

\section{Data Analysis}

\section{Stimulus Energy Calculation}

Increment energy $\left(\Delta \mathrm{E}\right.$, in $\left.\mathrm{cd} / \mathrm{m}^{2} . \mathrm{s}^{\mathrm{deg}}{ }^{2}\right)$ for each stimulus was calculated as the product of increment luminance $\left(\mathrm{cd} / \mathrm{m}^{2}\right)$, stimulus duration (s) and stimulus area $\left(\mathrm{deg}^{2}\right)$. This calculation was performed using Equation 1 with luminance values collected using a ColorCal-II device (stimulus: $L$, background: $\left.L_{b}\right)$, the number of frames within the stimulus $(f)$, the frame rate of the display $(r)$ and stimulus area $(A)$.

$$
\Delta E=\left(L-L_{b}\right)\left(\frac{f}{r}\right) A
$$

\section{Stimulus Duration}

The Bridgeman method ${ }^{42}$ was used to estimate stimulus duration $(t)$. This method measures stimulus duration from initial phosphor activation in the first frame to the last point of phosphor activity in the final frame of a presentation (Equation 2).

$$
t=[(f-1)(1000 / r)]+p
$$

Previous work ${ }^{44}$ has shown phosphor decay time $(p)$ for the P45 phosphor used in this study (Phillips FIMI MGD-403 display) to be invariant with luminance output at $1.8 \mathrm{~ms}$. For the purposes of this study, a constant value for $p$ was used (1.8 ms).

\section{Estimation of the Critical Duration}

Temporal summation functions were generated for each test location in all participants. Iterative two-phase regression analysis (Levenberg-Marquardt estimation, performed in MATLAB) was used to estimate the critical duration. As part of this analysis, the slope of the first line in the function was constrained to zero in line with Bloch's law, with the second line slope and intercept free to vary. The point at which the two lines intersect was taken as the critical duration. Data were excluded from further analysis if the software failed to estimate the critical duration (due to high variability in threshold measurements), or if the estimated critical duration was less than the shortest stimulus duration presented. Data were also excluded if the maximum luminance output of the display was below the threshold for a given stimulus duration (i.e., a ceiling effect). In addition to analyzing individual test locations for each subject, temporal summation functions were also generated with mean data from all participants $<30$ years $(n$ $=6)$ and those $\geq 60$ years $(n=6)$, respectively. For the purposes of statistical analysis, mean critical duration values were calculated for each hemifield (i.e., two values per subject). Where data for a given location were excluded from further analysis, the critical duration was taken as the estimate from the remaining location in that hemifield.

\section{Analysis of the Effect of Age on Contrast Thresholds}

The effect of age on energy contrast thresholds for both the shortest ( 1 frame) and longest duration stimuli ( 24 frames) was investigated using least-squares linear regression. The difference in the slope of linear regression functions was calculated and the statistical significance of this observed value examined using permutation analysis. ${ }^{45}$ Briefly, this analysis involved the random reassignment of threshold variables (without replacement) to one of two groups each matched in sample size to the original test data. Regression analysis was again performed for the groups and the difference between slope values calculated. This was repeated 5000 times and a distribution of calculated difference values produced. A $P$-value was then generated for the observed test value based upon its position in the distribution.

\section{Results}

A total of 108 localized temporal summation functions were generated in this study. The iterative two-phase regression analysis failed to produce a critical duration value in two data sets, owing to an abnormal spread of the data. Thus, these data were excluded. Example iterative temporal summation functions for individual test locations may be seen in Figure 1. Critical duration values are plotted as a function of age in Figure 2. Least squares linear regression analysis revealed there to be a small but non-statistically significant association between the critical duration and age (superior: $r^{2}=9.1 \times$ $10^{-9}, P=0.99$; inferior: $r^{2}=2.4 \times 10^{-5}, P=0.98$ ). Also, no notable difference in the shape of temporal summation functions is observed when comparing the average functions for the youngest ( $<30$ years) and oldest ( $\geq 60$ years) subject groups in Figure 3. Median critical duration estimates for each age group may be seen in the Table.

Although no association between temporal summation and age was observed, there was a statistically significant increase in threshold energy values for both the shortest (superior: $r^{2}=$ 0.48 , inferior: $r^{2}=0.55$, both $P<0.001$ ) and longest (superior: $r^{2}=0.51$, inferior: $r^{2}=0.43$, both $P<0.001$ ) stimulus durations, with increasing age (Fig. 4). Interestingly, there was no statistically significant difference in the slope of the linear regression lines for both the shortest and longest duration 


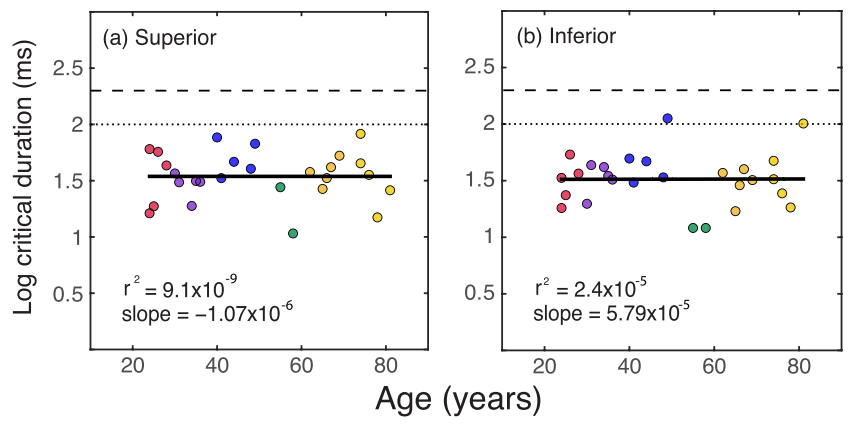

Figure 2. Critical duration estimates for participants of varying age collected using a $0.48^{\circ}$ diameter spot stimulus in the (a) superior hemifield and (b) inferior hemifield. Least-squares linear regression lines (black) are also included. The dasbed lines in each plot represent the stimulus durations used in conventional SAP (100 and $200 \mathrm{~ms}$ ).

stimuli when plotted as a function of age, examined using permutation analysis (superior: $P=0.91$, inferior: $P=0.81$ ). If a difference in summation were to be seen with age, the relationship between threshold and age for the longest and shortest stimuli would not be equal (i.e., a statistically significant difference in slopes would be observed).

\section{Discussion}

We observed no statistically significant association between the critical duration and age for a near-GIII $\left(0.48^{\circ}\right)$ stimulus, under the conditions of SAP. This is in agreement with previous work, ${ }^{34,35}$ albeit under experimental conditions closely matching those used in clinical tests of the visual field. This absence of change is observed despite a significant increase in contrast threshold for all stimulus durations and the optical and neural changes that occur in the aging eye.

The physiological underpinnings of temporal summation are a matter of significant debate within the literature. Current hypotheses suggest that the critical duration is determined by a combination of processing at the level of photoreceptors, RGCs, and cortical areas. ${ }^{31}$ As each of these regions is potentially disturbed in the aging process, it is somewhat surprising that no trend toward increasing temporal summation is observed. Despite this, significant questions remain as to why temporal summation is invariant with subject age in healthy observers.

Considering first summation at the level of the retina, it has been suggested that the action of light on photopigments and not photoreceptor structure is associated with temporal summation. ${ }^{25,46}$ Thus, should the volume and molecular structure of photopigments remain constant with increasing age, it is conceivable that no change in temporal summation will be found, irrespective of any morphologic changes in photoreceptor structure. Using a radioimmunoassay, Plantner and Barbour ${ }^{47}$ found the quantity of rhodopsin to be invariant of age and sex. In studies of retinal densitometry, no difference was observed in $\operatorname{rod}^{48}$ or cone ${ }^{12,49}$ photopigment density with increasing subject age, though these findings have been contested. ${ }^{50}$ Schefrin et al. ${ }^{51}$ hypothesized that the volume of rhodopsin remains invariant with age, despite age-related rod loss as a result of an increase in the area of outer segments to

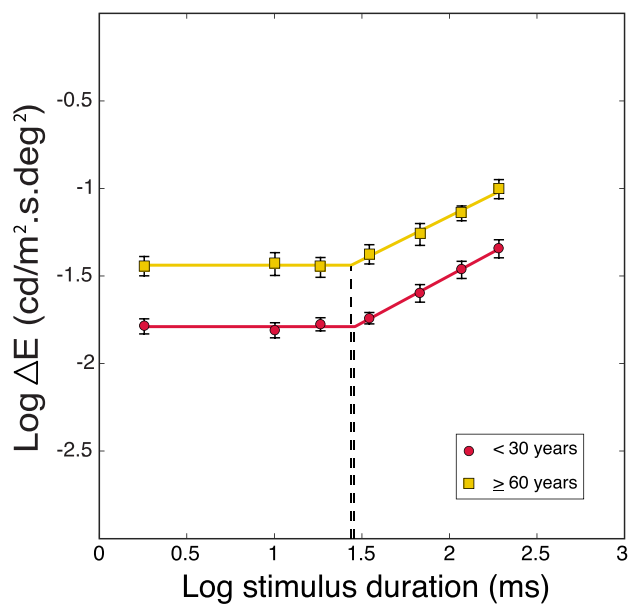

FIgURE 3. Average temporal summation functions for participants aged $<30$ years and $\geq 60$ years, respectively. Error bars represent $95 \%$ confidence intervals for the mean.

occupy the space vacated by necrotic rods. ${ }^{10}$ The time taken for photopigment regeneration following deisomerization is also thought to remain constant throughout life in the healthy visual system. ${ }^{12}$ Evidence for intact rod photoreceptor function with age may also be observed in the constant a-wave amplitude from scotopic ERG traces in participants aged 10 to 70 years. ${ }^{52}$

The loss of retinal ganglion ${ }^{14-16}$ and cortical cells ${ }^{19}$ with increasing age does not appear to influence temporal summation in healthy observers. A number of explanations may be proposed for this finding. The first centers on the size of the stimuli used in relation to the area of complete spatial summation, or Ricco's area. ${ }^{53}$ Previous work ${ }^{54,55}$ has shown that the area of the stimulus $\left(0.18 \mathrm{deg}^{2}\right)$ used in this study is likely to be larger than Ricco's area in healthy observers at the test locations examined. Considering this evidence, it is possible that our choice of stimulus area may cause subtle variations in both partial and complete temporal summation to be unobservable. Such spatiotemporal interactions have been proposed by previous authors, ${ }^{56,57}$ while Owen ${ }^{58}$ suggested that true complete temporal summation may only be seen with stimuli smaller than or equal to Ricco's area. Wide angle light scatter, and thus the projected area of a stimulus on the retina, is known to increase with age. ${ }^{59}$ As the effective stimulus area is increased, there is the potential for the critical duration to be artificially reduced, therefore masking any changes in temporal summation that might otherwise be observable as a result of age-related neural loss. To date no study has tested this hypothesis using an adaptive optics system to minimize the aberrative effects of the eye's optics. Increased forward light scatter has also been put forward as a possible explanation for an unobservable age-related change in the area of complete spatial summation (Ricco's area) in healthy observers, based on an equal and opposite effect of simulated neural and optical aging (Ref. 54 and Redmond T, et al. IOVS 2011;52:ARVO EAbstract 5503).

It has previously been hypothesized that temporal summation is at least partly moderated by means of filters

TABLE. Median (IQR) Critical Duration Estimates for Different Age Groups Examined in This Study

\begin{tabular}{cccccc}
\hline Age Group, $y$ & $\mathbf{2 0 - 3 0}$ & $\mathbf{3 1 - 4 0}$ & $\mathbf{4 1 - 5 0}$ & $\mathbf{5 1 - 6 0}$ & $>\mathbf{6 0}$ \\
\hline Median (IQR) critical duration, ms & $33.5(18.3-51.2)$ & $31.9(30.6-36.7)$ & $46.7(33.8-67.3)$ & $12.1(11.1-23.8)$ & $34.5(26.4-43.4)$ \\
\hline
\end{tabular}




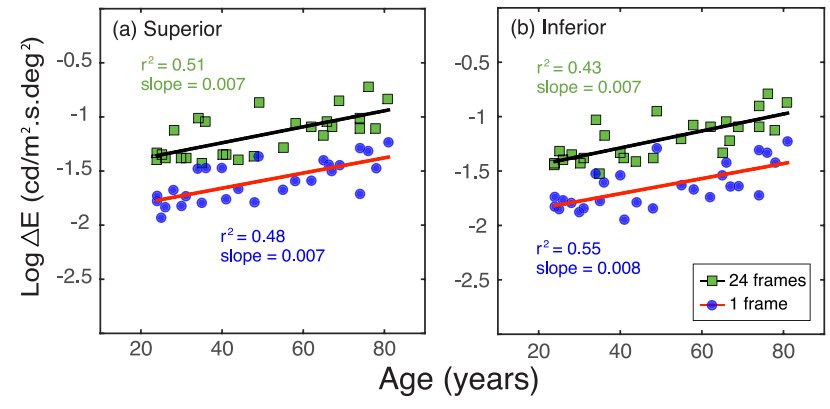

Figure 4. Effect of age on threshold energy values for the shortest (1 frame, $1.8 \mathrm{~ms}$ ) and longest ( 24 frames, $191.9 \mathrm{~ms}$ ) stimulus durations in the (a) superior and (b) inferior hemifields. Data points represent the mean threshold value for the two test locations examined in each hemifield.

at the level of the visual cortex. ${ }^{30}$ Considering the presence of such filters, a simple explanation may be that the tuning of temporally selective cells in the visual cortex is unaffected by aging. This hypothesis is interesting, given the suggestions that both the CFF frequency ${ }^{60}$ and perceptual mechanisms related to the detection of moving stimuli $^{61}$ (both of which are thought to be reflective of temporal processing in the cortex) vary as a function of age. It is also possible, however, that a neural remodeling occurs in the cortex secondary to cell loss in lower regions of the visual pathway. Such alterations in structure have previously been demonstrated in animal models. Gilbert and Wiesel ${ }^{62}$ induced scotomata in the visual field of monkeys and cats through the application of laser burns to the retina and found an immediate increase in the receptive field diameter of the remaining cortical cells near the edge of the scotoma. This adaptive response was attributed, in part, to synaptic reorganization in the cortex. Although such alterations may be limited to increasing the spatial projection of cortical receptive fields following cell loss, it is possible that similar synaptic changes develop to maintain constant temporal summation throughout life.

The results of this study suggest that the use of presentation durations in the range of 100 to $200 \mathrm{~ms}$ will have no influence on the ability of SAP to detect age-related changes in visual sensitivity in the absence of pathology. In other words, for all stimulus durations examined in this study, there was no difference in the vertical separation of the summation functions for the youngest and oldest observers (Fig. 3). This result is similar to that reported by Dannheim and Drance ${ }^{35}$ for an achromatic $0.75^{\circ}$ stimulus presented on a $3.18 \mathrm{~cd} / \mathrm{m}^{2}$ background. In selecting an appropriate stimulus duration to optimize the sensitivity of SAP to detect ocular disease, it is essential that any change in temporal summation as a result of the disease process be quantified.

\section{Conclusions}

No variation in temporal summation was detected with increasing age for achromatic spot stimuli. This observation may at least be partly explained by the interaction of spatial and temporal processing, optical changes or possibly a neural reorganization in the aging visual system. Although age-related changes in the architecture of the retina and higher visual areas do not appear to influence temporal summation, it is currently unclear if pathologic processes such as glaucoma disrupt this aspect of temporal visual function. This is investigated in the accompanying paper. $^{41}$

\section{Acknowledgments}

Supported by a $\mathrm{PhD}$ studentship from the Department for Employment and Learning, Northern Ireland (PJM), and in part by the National Institute for Health Research (NIHR) Biomedical Research Centre based at Moorfields Eye Hospital NHS Foundation Trust and UCL Institute of Ophthalmology (PJM, DFG-H). DFG-H's chair at UCL is supported by funding from the International Glaucoma Association. The views expressed are those of the authors and not necessarily those of the NHS, the NIHR, or the Department of Health.

Disclosure: P.J. Mulholland, Heidelberg Engineering (R); T. Redmond, Heidelberg Engineering (F); D.F. Garway-Heath, Carl Zeiss Meditec (F, R), Heidelberg Engineering (F, R), P; M.B. Zlatkova, None; R.S. Anderson, Heidelberg Engineering (F, R)

\section{References}

1. Wright CE, Drasdo N. The influence of age on the spatial and temporal contrast sensitivity function. Doc Ophthalmol. 1985; 59:385-395.

2. Elliott D, Whitaker D, MacVeigh D. Neural contribution to spatiotemporal contrast sensitivity decline in healthy ageing eyes. Vision Res. 1990;30:541-547.

3. Weale RA. Senile changes in visual acuity. Trans Ophthalmol Soc U K. 1975;95:36-38.

4. Elliott DB. Contrast sensitivity decline with ageing: a neural or optical phenomenon? Ophthalmic Physiol Opt. 1987;7:415419.

5. Artal P, Ferro M, Miranda I, Navarro R. Effects of aging in retinal image quality. J Opt Soc Am A. 1993;10:1656-1662.

6. Hemenger RP. Intraocular light scatter in normal vision loss with age. Appl Opt. 1984;23:1972.

7. Kadlecova V, Peleska M, Vasko A. Dependence on age of the diameter of the pupil in the dark. Nature. 1958;182:15201521.

8. Weale RA. Age and the transmittance of the human crystalline lens. J Physiol. 1988;395:577-587.

9. Marshall J, Grindle J, Ansell PL, Borwein B. Convolution in human rods: an ageing process. Br J Ophthalmol. 1979;63: 181-187.

10. Curcio CA, Millican CL, Allen KA, Kalina RE. Aging of the human photoreceptor mosaic: evidence for selective vulnerability of rods in central retina. Invest Ophthalmol Vis Sci. 1993;34:3278-3296.

11. Marshall J. Aging changes in human cones. In: Shimizu K, Oosterhuis A, eds. 23rd International Congress on Ophthalmology. Amsterdam: Excerpta Medica; 1979:101.

12. van Norren D, van Meel GJ. Density of human cone photopigments as a function of age. Invest Ophthalmol Vis Sci. 1985;26:1014-1016.

13. Song H, Chui TY, Zhong Z, Elsner AE, Burns SA. Variation of cone photoreceptor packing density with retinal eccentricity and age. Invest Ophthalmol Vis Sci. 2011;52:7376-7384.

14. Anderson RS, McDowell DR. Peripheral resolution using stationary and flickering gratings: the effects of age. Curr Eye Res. 1997;16:1209-1214.

15. Curcio CA, Drucker DN. Retinal ganglion cells in Alzheimer's disease and aging. Ann Neurol. 1993;33:248-257.

16. Alamouti B, Funk J. Retinal thickness decreases with age: an OCT study. Br J Ophthalmol. 2003;87:899-901.

17. Vrabec F. Senile changes in the ganglion cells of the human retina. Br J Ophthalmol. 1965;49:561-572.

18. Eliasieh K, Liets LC, Chalupa LM. Cellular reorganization in the human retina during normal aging. Invest Ophthalmol Vis Sci. 2007; 48:2824-2830. 
19. Devaney KO, Johnson HA. Neuron loss in the aging visual cortex of man. J Gerontol. 1980;35:836-841.

20. McFarland RA, Warren AB, Karis C. Alterations in critical flicker frequency as a function of age and light: dark ratio. $J$ Exp Psychol. 1958;56:529-538.

21. Bloch AM. Experiences sur la vision. C R Soc Biol (Paris). 1885;37:493-495.

22. Barlow HB. Temporal and spatial summation in human vision at different background intensities. J Physiol (Lond). 1958; 141:337-350.

23. Saunders RM. The critical duration of temporal summation in the human central fovea. Vision Res. 1975;15:699-703.

24. Kahneman D, Norman J. The time-intensity realtion in visual perception as a function of observer's task. $J$ Expt Psychol. 1964;68:215-220.

25. Hartline HK. A quantitative and descriptive study of the electric response to illumination of the arthropod eye. $A m \mathrm{~J}$ Physiol. 1928;83:466-483.

26. Hood DC, Grover BG. Temporal summation of light by a vertebrate visual receptor. Science. 1974;184:1003-1005.

27. Granit R, Davis W. Comparative studies on the peripheral and central retina IV: temporal summation of subliminal visual stimuli and the time course of the excitatory after-effect. Am J Physiol. 1931;98:644-653.

28. Baumgardt E, Hillmann B. Duration and size as determinants of peripheral retinal response. J Opt Soc Am. 1961;51:340-344.

29. Wilson ME. Spatial and temporal summation in impaired regions of the visual field. J Physiol. 1967;189:189-208.

30. Swanson WH, Pan F, Lee BB. Chromatic temporal integration and retinal eccentricity: psychophysics, neurometric analysis and cortical pooling. Vision Res. 2008;48:2657-2662.

31. Battersby W, Schuckman H. The time course of temporal summation. Vision Res. 1970;10:263-273.

32. Fulton AB, Hansen RM, Yeh YL, Tyler CW. Temporal summation in dark-adapted 10-week old infants. Vision Res. 1991;31:1259-1269.

33. Eriksen C, Hamlin R, Breitmeyer R. Temporal factors in visual perception as related to aging. Attention Percept Psychophys. 1970;7:354-356.

34. Sturr J, Church K, Taub H. Temporal summation functions for detection of sine-wave gratings in young and older adults. Vision Res. 1988;28:1247-1253.

35. Dannheim F, Drance S. Studies of temporal summation of central retinal areas in normal people of all ages. Ophthalmic Res. 1971;2:295-303.

36. Mulholland PJ, Redmond T, Garway-Heath DF, Zlatkova MB, Anderson RS. Estimating the critical duration for temporal summation of standard achromatic perimetric stimuli. Invest Ophthalmol Vis Sci. 2014;56:431-437.

37. International Council of Ophthalmology. Perimetric Standards and Perimetric Glossary of the International Council of Ophthalmology. London: Dr. W. Junk bv Publishers; 1979.

38. Johnson CA. Psychophysical factors that have been applied to clinical perimetry. Vision Res. 2013;90:25-31.

39. Aulhorn E, Harms H. Visual perimetry. In: Jameson D, Hurvich L, eds. Visual Psychophysics. Heidelberg: Springer Berlin Heidelberg. 1972:102-145.

40. Mulholland PJ, Redmond T, Garway-Heath DF, Zlatkova MB, Anderson RS. Estimating the critical duration for temporal summation of standard achromatic perimetric stimuli. Invest Ophthalmol Vis Sci. 2014;56:431-437.

41. Mulholland PJ, Redmond T, Garway-Heath DF, Zlatkova MB, Anderson RS. Temporal summation of perimetric stimuli in early glaucoma. Invest Ophthalmol Vis Sci. 2015;56:64736482.

42. Bridgeman B. Durations of stimuli displayed on video display terminals: $(\mathrm{n}-1) / \mathrm{f}+$ persistence. Psychol Sci. 1998;9:232233.

43. Levitt H. Transformed up-down methods in psychoacoustics. $J$ Acoust Soc Am. 1971;49(suppl 2):467+.

44. Mulholland PJ, Zlatkova MB, Redmond T, Garway-Heath DF, Anderson RS. Effect of varying CRT refresh rate on the measurement of temporal summation. Ophthalmic Physiol Opt. 2015;35:582-590.

45. Redmond T, Anderson RS, Russell RA, Garway-Heath DF. Relating retinal nerve fiber layer thickness and functional estimates of ganglion cell sampling density in healthy eyes and in early glaucoma. Invest Ophthalmol Vis Sci. 2013;54:21532162.

46. Hartline $\mathrm{H}$. Intensity and duration in the excitation of single photoreceptor units. J Cell Comp Physiol. 1934;5:229-247.

47. Plantner JJ, Barbour HL, Kean EL. The rhodopsin content of the human eye. Curr Eye Res. 1988;7:1125-1129.

48. Liem AT, Keunen JE, van Norren D, van de Kraats J. Rod densitometry in the aging human eye. Invest Ophthalmol Vis Sci. 1991;32:2676-2682.

49. Elsner AE, Berk L, Burns SA, Rosenberg PR. Aging and human cone photopigments. J Opt Soc Am A. 1988;5:2106-2112.

50. Keunen JE, van Norren D, van Meel GJ. Density of foveal cone pigments at older age. Invest Ophthalmol Vis Sci. 1987;28: 985-991.

51. Schefrin BE, Bieber ML, McLean R, Werner JS. The area of complete scotopic spatial summation enlarges with age. $J$ Opt Soc Am A Opt Image Sci Vis. 1998;15:340-348.

52. Weleber RG. The effect of age on human cone and rod ganzfeld electroretinograms. Invest Ophthalmol Vis Sci. 1981; 20:392-399.

53. Ricco A. Relazione fra il minimo angolo visuale e l'intensità luminosa. Memorie della Regia Academia di Scienze, lettere ed arti in Modena. 1877;17:47-160.

54. Redmond T, Zlatkova MB, Garway-Heath DF, Anderson RS. The effect of age on the area of complete spatial summation for chromatic and achromatic stimuli. Invest Ophthalmol Vis Sci. 2010;51:6533-6539.

55. Swanson WH, Felius J, Pan F. Perimetric defects and ganglion cell damage: interpreting linear relations using a two-stage neural model. Invest Ophthalmol Vis Sci. 2004;45:466-472.

56. Sperling H, Jolliffe C. Intensity-time relationship at threshold for spectral stimuli in human vision. J Opt Soc Am A. 1965;55: 191-198.

57. Baumgardt E. Visual spatial and temporal summation. Nature. 1959;184:1951-1952.

58. Owen WG. Spatio-temporal integration in the human peripheral retina. Vision Res. 1972;12:1011-1026.

59. IJspeert JK, de Waard PW, van den Berg TJ, de Jong PT. The intraocular straylight function in 129 healthy volunteers; dependence on angle, age and pigmentation. Vision Res. 1990;30:699-707.

60. Wells EF, Bernstein GM, Scott BW, Bennett PJ, Mendelson JR. Critical flicker frequency responses in visual cortex. Exp Brain Res. 2001;139:106-110.

61. Mendelson JR, Wells EF. Age-related changes in the visual cortex. Vision Res. 2002;42:695-703.

62. Gilbert CD, Wiesel TN. Receptive field dynamics in adult primary visual cortex. Nature. 1992;356:150-152. 